\section{Facharztprüfung zur Erlangung des Facharzttitels FMH für Intensivmedizin}

Aufgrund des Weiterbildungsprogrammes und des Beschlusses des Zentralvorstandes der FMH vom 28. Dezember 2000 ist das Bestehen der Facharztprüfung für alle Kandidatinnen und Kandidaten, welche ihre Weiterbildung nach dem 31. Dezember 2002 abschliessen, Voraussetzung zur Erlangung des Facharzttitels FMH für Intensivmedizin. Näheres zu den Übergangsbestimmungen und Ausnahmen ist in der Schweizerischen Ärztezeitung Nr. 6 vom 7. Februar 2001 publiziert.
1. Teil, schriftliche Prüfung: Donnerstag, 15. November 2001, in Bern. Diese Prüfung besteht aus 120 Multiple-choice-Fragen.

2. Teil, mündliche Prüfung: Donnerstag, 31. Januar 2002, in Bern. Das mündliche Examen dauert 1 Stunde.

Prüfungsgebühr: Die Fachgesellschaft erhebt eine Prüfungsgebühr von Fr. 700.-.

Anmeldung: Die Anmeldeformulare können bezogen werden beim Sekretariat der Schweizerischen Gesellschaft für Intensivmedizin, Postfach 1085, 3110 Münsingen, Tel. 03172207 21, Fax 031 7220722.

Anmeldefrist: 31. August 2001

Das Weiterbildungsprogramm inklusive Prüfungsbedingungen wurde auf der Homepage der FMH (www.fmh.ch $\rightarrow$ WB-Programme) publiziert. Diese Unterlagen können im Sekretariat der FMH, Abteilung Weiter- und Fortbildung, Elfenstrasse 18, 3000 Bern 16, Tel. 03135911 11, oder im Sekretariat der SGI angefordert werden.

\section{Examen de spécialiste en vue de l'obtention du titre de spécialiste FMH en médecine intensive}

Conformément au programme de formation postgraduée et à la décision du Comité central de la FMH du 28 décembre 2000, la réussite de l'examen de spécialiste est une condition requise pour les candidats au titre FMH en médecine intensive qui termineront leur formation postgraduée après le 31 décembre 2002. Pour de plus amples renseignements concernant les dispositions transitoires et les dérogations, veuillez vous référer à la publication du Bulletin des médecins suisses no 6, du 7 février 2001. $1^{\text {re }}$ partie, examen écrit: Jeudi, 15 novembre 2001, à Berne. L'examen écrit se compose de 120 questions à choix multiple.

$2^{\mathrm{e}}$ partie, examen écrit: Jeudi, 31 janvier 2001, à Berne. L'examen oral dure 1 heure.

Taxe d'examen: La Société de discipline médicale prélève une taxe d'examen de Fr. 700.-.

Inscription: Les formulaires d'inscription peuvent être obtenus auprès du Secrétariat de la Société Suisse de Médecine Intensive, Case postale 1085, 3110 Münsingen, tél. 03172207 21, fax 031 7220722.

Délai d'inscription: 31 août 2001

Le programme de formation postgraduée, qui comprend les modalités de l'examen de spécialiste, a été publié sur la page d'accueil de la FMH (www.fmh.ch $\rightarrow$ Programmes de FP). Ce programme peut être demandé au Secrétariat de la FMH, Dép. de la formation postgraduée et continue, Elfenstrasse 18, 3000 Berne 16, tél. 03135911 11, ou au secrétariat de la SSMI. 